\title{
ИСПОЛЬЗОВАНИЕ ФИНАНСОВЫХ ИНСТРУМЕНТОВ В СОВРЕМЕННОЙ РОССИЙСКОЙ ЭКОНОМИКЕ
}

\section{USE OF FINANCIAL INSTRUMENTS IN THE MODERN RUSSIAN ECONOMY}

V. Zaitsev

Summary. The use of various financial instruments by companies is one of the key factors of its success in the market. Timely selection of the correct financial instruments is the most important task of company management. To accomplish this task, there are various techniques, some of which are based on defining the life cycles of an organization. Sources of financing are the channels through which it is possible to raise funds. As a rule, a careful analysis of the project or the factors affecting their well-being is used for financing. There are various theories of the life cycles of companies, in this work we will consider some of them and propose our theory of defining the life cycle. Based on the life cycle, we will present the optimal sources of financing. In this paper, we will also consider the life cycles of companies that distinguish the scientific community, and characterize them. Based on the life stages proposed by various researchers, we will choose the most optimal ones for research.

Keywords: financial instrument, life cycle, stocks, investing, derivatives, swaps, structured products, initial public offering.

\section{Ввеление}

B современной российской экономике существует большое количество финансовых инструментов. Жизненные циклы компаний оказывают значительное влияние на выбор оптимального источника финансирования. Изучение жизненных циклов организаций осуществляется различными учеными с использованием понятий «стратегия» и «финансы». В соответствии с каждым типом жизненного цикла исследователи предлагают различные методы управления компанией. Одна из главных задач авторов, занимающихся изучением жизненных циклов, является разработка и применение наиболее подходящих методов управления. Целью данной статьи является подбор оптимальных источников финансирования в соответствии с жизненными стадиями компаний.

\section{Мето ология}

Методология данного исследования основывается на публикациях в области финансов и жизненных ци-

\author{
Зайцев Владислав Александрович \\ Аспирант, РЭУ им. Г.В. Плеханова, г. Москва \\ vladz2210@mail.ru
}

Аннотация. Использование компаниями различных финансовых инструментов является одним из ключевых факторов ее успеха на рынке. Своевременный выбор корректных финансовых инструментов является важнейшей задачей менеджмента компаний. Для реализации данной задачи существуют различные методики, одни из которых основываются на определении жизненных циклов организации. Источники финансирования - это каналы, через которые возможно привлечь финансовые средства. Как правило, основой для финансирования является тщательный анализ проекта или компании и факторов, влияющих на их благосостояние. Существует различные теории жизненных циклов компаний, в данной статье рассмотрим некоторые из них и предложим свою теорию определения жизненного цикла. На основании выбранного жизненного цикла приведем оптимальные источники финансирования. Также в данной работе рассмотрим существующие жизненные циклы компаний, которые выделяет научное сообщество, и охарактеризуем их. На основании предложенных различными исследователями жизненных стадий, выберем для исследования наиболее оптимальные.

Ключевые слова: финансовый инструмент, жизненный цикл, акции, инвестирование, деривативы, своп, структурированные продукты, первичное размещение акций.

клов организаций, методы обобщения, систематизации, логики.

В процессе данного исследования были изучены работы ведущих мировых исследователей в области финансов и жизненных циклов организаций, работы были обобщены, систематизированы и выделены основные заключения исследователей.

Исследование подтверждается статистическими данными, которые были взяты из базы данных Capital IQ.

Перечисленные методы в рамках темы исследования помогают провести качественный анализ данных и информации, выработать методику по улучшению финансового состояния компаний.

\section{Аитературный обзор}

Еще в 60-х годах двадцатого века было исследователь Дж. Гарднер предложил рассматривать организации с точки зрения живого организма. Он утверждал: 
“Как люди и растения, организации также имеют свой жизненный цикл. Они проходят время зеленой и гибкой юности, расцвета и сучковатой старости... Организации могут преодолеть время от юности до старости за два или три десятилетия, а могут жить веками".

Такое суждение предполагает, что, как и у человека, организации имеют свои психологические установки и законы. Организации могут, как и люди сталкиваться с кризисами и преодолевать их, переходить на новые уровни развития, учиться, достигать расцвета и умирать. Можно привести еще одно сравнение: “...смотришь на иную фирму: ей отроду три года, а она уже как постаревший ребенок - дряхлое руководство, апатичные сотрудники, никому ничего не надо...".

Организации очень индивидуальны в своем развитии, оно зависит от отрасли, от размеров самой организации, от численности людей, от ее возраста, от ее специфики и даже географического расположения мощностей.

Жизненный цикл организации может не коррелировать с ее возрастом. Однако исследователь Л. Грейнер, изучая жизненные циклы организаций на протяжении 30 лет утверждает, что в современном мире организации стали умирать гораздо чаще.

В западной литературе жизненные циклы организаций рассматриваются как периоды жизни с одинаковыми ценностными установками, оказывающих влияние на задачи менеджеров. Если организация принципиально изменяет свои ценности и установки, то она претерпевает изменение своего жизненного цикла.

Исследователи выделяют в своих работах минимум десять моделей развития организаций. Интересным фактом является то, что все десять моделей были выделены в Америке во второй половине двадцатого века.

А. Даун: “Движущие силы роста” (1967) - это одна из самых первых моделей, которая появилась на основе правительственных комитетов. Он предложил три стадии развития организации. Первая стадия - рождение, возникает в процессе борьбы за независимость. Данной стадии свойственно стремление обрести ресурсы для достижения «порога выживания». Вторая стадия - рост, которая характеризуется расширением границ и инновационным развитием. Третья стадия замедление, главная черта которой - бюрократия, которая характеризуется формализацией и контролем.

Следующие исследователи области жизненных циклов - это Г.Липпитт и У. Шмидт. В своей работе «Управленческое участие» (1967) начали разрабатывать модель жизненных циклов, применимую к частным организациям. Данные исследователи также выдвинули три стадии жизненных циклов: рождение, юность и зрелость. На стадии рождения зарождается жизнеспособность, на стадии юности происходит устойчивое развитие, а на стадии зрелости достигается уникальность и приспосабливаемость к окружающей среде.

Б. Скотт в своей работе "Стратегия и структура" (1971) выделяет три стадии: от неформальной до формализованной бюрократии, и после до разных конгломератов.

Следующий рассматриваемый исследователь Л. Грейнер, в своей работе «Проблемы лидерства на стадиях Эволюции и Революции» (1972) выдвигает теорию, что будущее компании определяется ее организационной структурой. Л. Грейнер в доказательство своей теории опирается на исследования психологов, которые утверждают, что поведение основывается на предыдущем опыте, а не на будущем. Сравнивая компанию с человеком, он выдвигает ряд стадий, которые должна пройти компания - эволюционное развитие.

Исследователь У. Торберт в работе “Ментальность членов организации" (1974) тесно связывает организационное развитие с развитием общности персонала. Эволюция происходит от индивидуального развития к коллективному. Однако в работе механизмы развития не уточняются.

Ф.Лиден в работе “Функциональные проблемы" (1975) начинает свою теорию с момента адаптации и завоевания собственной ниши во внешней среде. Здесь компания использует инновации. Далее компании приобретают ресурсы, после чего придается значение цели и образ поведения. На своей последней стадии организации поддерживают свои поведенческие стереотипы.

Д. Кац и Р. Кан в работе “Организационная структура" (1978) выдвигают теорию простых систем, устойчивую стадию и стадию разработки структур. Организации в данной работе рассматриваются как открытые системы, которые взаимодействуют с внешней средой.

После публикации работы различные социальные организации рассматривались как открытые системы, взаимодействующие с окружающей средой.

И. Адизес в работе «Теория жизненных циклов организации» (1979) рассматривает организации с позиции живого организма. Как и живые организмы компании проходят поэтапное развитие, которое определяется неизбежностью наступления обязательных предусмотренных циклов. Однако концепция предусматривает 
невозможность избегания некоторых неблагоприятных фаз. Концепция концентрируется на управляемости и приспосабливаемости компаний.

Как и живой организм компаниям свойственны болезни, согласно концепции Адизеса. Существуют болезни взросления, которые практически невозможно избежать (схожесть с детскими инфекционными заболеваниями) и патологии, которые зарождаются и при позднем диагностировании компания самостоятельно уже не может их победить. При правильном управленческом подходе компания может довольно долго находиться на стадии своего расцвета, что отличает ее от живого организма.

Свою неповторимую теорию касательно жизненных циклов организаций выдвинул Дж. Кимберли в своей работе «Внешний социальный контроль, структура работы и отношения с окружающей средой» (1979). Исследователь изучал появление и развитие медицинских школ. Кимберли выдвигает теорию, что первая стадия развития организации появляется еще до ее зарождения. Данная стадия характеризуется появлением первых идей и возникновении миссии. Далее наступает вторая стадия - это формирование рабочей силы. На дальнейших стадиях развития организации начинают процесс формализации своей деятельности, организации становятся предсказуемыми в своих действиях.

\section{Результаты \\ и обсужАение}

При прохождении компаний через разные стадии жизненных циклов, становятся различными и источники финансирования компаний. В своей работе Е. Отекина, подтверждая данное предположение, выделяет следующие источники финансирования в зависимости от стадии жизненного цикла: [3]

1. Стадия «Выхаживание» - собственный капитал (3F);

2. Стадия «Младенчество» - банковские кредиты;

3. Стадия «Давай-давай» - векселя, облигации;

4. Стадия «Юность» - евробонды, синдицированные кредиты;

5. Стадия «Расцвет» - Private placement, pre-IPO;

6. Стадия «Стабильность» - IPO.

На раннем этапе становления, а именно на этапе «выхаживания», у компаний существует крайне ограниченные источники финансирования. Основным источником денежных средств как правило являются собственные средства акционеров (Family, Friends, Fools - 3F). Поскольку на начальном этапе у компаний отсутствует кредитная история и обеспечение, то многие банки отказывают в финансировании.
На этапе «младенчества» у компаний начинают появляться денежные средства в виде нераспределенной прибыли. На данном этапе у компаний начинает появляться банковское финансирование, однако при финансовых показателях, характеризующие стадию «младенчества» банки предлагают кредиты по невыгодным для компаний условиям. На этапе «роста» компании, как правило, уже свободно выходят на долговой рынок, выпуская облигации или векселя, тем самым привлекая инвесторов. Привлечение финансирования через долговой рынок имеет ряд преимуществ перед банковским кредитом, а именно: формирование публичной истории заимствования, избежание попадания в «кредитный капкан» со стороны одного крупного инвестора - банка.

Однако и банковское кредитование имеет ряд своих преимуществ, таких как: малый срок операции выдачи кредита по сравнению с выпуском облигаций, конфиденциальность информации, отсутствие затрат на эмиссию.

Свое участие в долговых обязательствах, компании, как правило, начинают с использованием векселей [4].

Как и любой финансовый инструмент, векселя имеют некоторые недостатки:

- короткий срок привлечения инвестиций;

- для компаний-эмитентов векселей выплаты по данным долговым бумагам зачастую выше процентной ставки привлечения банковского кредита;

- небольшое количество потенциальных инвесторов;

- бумажная форма, которая может оказаться поддельной, или наличие дефектов на векселе.

Принимая во внимания все вышеперечисленные недостатки, компании, как правило, переходят к использованию долгосрочных финансовых инструментов - облигаций. Облигации имеют следующие преимущества:

- больший срок обращения данной долговой бумаги (возможно обращение свыше 7 лет);

- облигации могут обращаться на фондовом рынке, что делает заимствования компаний публичными;

- выплаты по процентам обычно ниже, чем выплаты по векселям или банковским кредитам;

- возможность привлечения больших объемов денежных средств [6];

Зачастую у компаний наступают моменты, когда кредитов отдельно взятых банков становится недостаточно, тогда компании начинают использовать син- 
Таблица 1. Виды структурированных финансовых инструментов

\begin{tabular}{|c|c|c|c|}
\hline Наименование & $\begin{array}{l}\text { Инструменты, использующие } \\
\text { доход от малорискованных } \\
\text { финансовых инструментов }\end{array}$ & $\begin{array}{l}\text { Инструменты, } \\
\text { предполагающие продажу } \\
\text { одних финансовых } \\
\text { инструментов с целью } \\
\text { покупки других, приносящих } \\
\text { доход }\end{array}$ & $\begin{array}{l}\text { Инструменты, работающие } \\
\text { по принципу «финансового } \\
\text { рычага» }\end{array}$ \\
\hline Характеристика & $\begin{array}{l}\text { Отсутствие риска, небольшая } \\
\text { доходность }\end{array}$ & $\begin{array}{l}\text { Умеренный риск, потенциально } \\
\text { высокий уровень доходности }\end{array}$ & $\begin{array}{l}\text { Высокий риск, высокий уровень } \\
\text { доходности }\end{array}$ \\
\hline Механизм & $\begin{array}{l}\text { Инвестированные } \\
\text { средства делятся на две } \\
\text { части. Первая часть } \\
\text { вкладывается в инструменты } \\
\text { с фиксированной доходностью, } \\
\text { вторая часть вкладывается } \\
\text { в производные финансовые } \\
\text { инструменты }\end{array}$ & $\begin{array}{l}\text { Состоят из опционов, } \\
\text { позволяющих инвестору } \\
\text { получить требуемый уровень } \\
\text { доходности, однако нет } \\
\text { гарантии полного возврата } \\
\text { инвестированных средств }\end{array}$ & $\begin{array}{l}\text { Состоят из фьючерсов } \\
\text { (форвардов), позволяют } \\
\text { инвестору получать } \\
\text { повышенный доход при } \\
\text { благоприятном сценарии } \\
\text { развития рынка, однако } \\
\text { движение рынка может быть } \\
\text { и неблагоприятным }\end{array}$ \\
\hline Примеры & $\begin{array}{l}\text { Различные комбинации } \\
\text { банковского депозита или } \\
\text { государственных облигаций } \\
\text { со стандартным опционом колл }\end{array}$ & $\begin{array}{l}\text { комбинации банковского } \\
\text { депозита или государственных } \\
\text { облигаций со стандартным } \\
\text { опционом пут }\end{array}$ & $\begin{array}{l}\text { В основе лежит базовый актив, } \\
\text { по нему предполагается } \\
\text { положительное движение. } \\
\text { Доход заключается в виде } \\
\text { использования форвардов } \\
\text { на данный базовый актив }\end{array}$ \\
\hline
\end{tabular}

дицированные кредиты. Главными преимуществами таких кредитов является их невысокая стоимость привлечения и короткий срок подготовки (в течение трех месяцев). Недостатками такого вида кредита является короткий срок привлечения (1-2 года) и относительно небольшой объем (менее 50 миллионов долларов).

Компании, находящиеся на этапе «роста», повысив свою узнаваемость среди потенциальных инвесторов через выпуск разного рода долевых бумаг, переходят к долевому финансированию [6].

Начало долевого финансирования компаний зачастую является эмиссия акций или для стратегического инвестора, или для портфельного. К плюсам второго варианта можно и отнести то, что включение в капитал компании финансового института с положительной репутацией будет являться хорошей деловой репутацией компании-эмитента.

Источники финансирования - это каналы, через которые возможно привлечь финансовые средства. Как правило, основой для финансирования является тщательный анализ проекта или компании и факторов, влияющих на их благосостояние.

Глобально существуют два источника финансирования:
1. Внутренние источники;

2. Внешние источники (привлеченные средства) [7].

Внутренние источники - собственные средства компании.

Внешние источники - финансирование извне, которое в свою очередь подразделяется на заемные и привлеченные средства.

На сегодняшний день разнообразие финансовых инструментов, представленных на финансовом рынке, очень велико. В современных рыночных условиях особый интерес вызывают структурированные финансовые инструменты. Структурированные финансовые инструменты - это новая тенденция современной экономики, представляющая высокий интерес для инвесторов. В западном мире сектор структурированных финансовых инструментов развивается в течение десяток лет, в России они получили распространение сравнительно недавно. Основное преимущество структурированных финансовых инструментов - это возможность нахождения баланса между риском и доходностью для инвестора.

Многие банки и инвестиционные компании предлагают свои услуги в создании структурированных продуктов. Среди российских банков и инвестиционных 
компаний можно выделить следующие: «Sberbank CIB», «Восточный банк», «Альфа капитал», «Открытие» и т.д.

Рассмотрим основные виды структурированных финансовых инструментов.

Своп - это соглашение о будущем обмене денежными потоками в различные моменты времени. В основе свопа лежит юридическое соглашение между сторонами и определенный базовый актив.

В современной российской экономике рынок свопов преимущественно является внебиржевым, поэтому сделки заключаются посредником, который является гарантом получение каждой стороной платежей по свопу. При введении в своп-соглашение третьей стороны, это значительно снижает риск невыполнения своих обязательств каждой из сторон сделки. На сегодняшний день на внебиржевом рынке происходит порядка 90\% всех сделок с деривативами. Биржевые деривативы имеют большую ликвидность, однако, по сравнению с внебиржевыми деривативами, зачастую не обеспечивают требуемой компаниями гибкости [9].

На стадии «расцвета» большинство компаний могут привлекать финансирование за счет облигаций. Данный финансовый инструмент требует хорошей деловой репутации компании. Облигации могут выступать не только в роли привлечения финансирования, а также в качестве «проводника» в инвестиционное сообщество.

При своем дальнейшем развитии компании могут начать поиск финансирования на зарубежных рынках капитала с целью получения более выгодных кредитов и на лучших условиях с точки зрения стоимости. На данной стадии жизненного цикла компании могут использовать так называемые еврооблигации (Eurobonds), кредитные ноты (Credit Linked Notes, CLN), ноты участия в кредите (Loan Participation Notes, LPN). Выпуск кредитных нот и евробондов ограничены: для кредитных нот ограничением как правило является 100 миллионов долларов США, для евробондов ограничение является шире - порядка 300 миллионов долларов США. При переходе компаний на финансирование посредством выпуска евробондов и кредитных нот она начинает путь публичной кредитной истории. Публичная кредитная история оказывает значительное положительное влияние на привлекательность IPO компаний, а также снижает стоимость привлечения капитала. В момент выхода компаний на IPO важно сделать акцент на привлечении именно стратегического инвестора, который сможет оказать влияние на дальнейшее успешное развитие. Поиск такого стратегического инвестора является непростой задачей, поскольку рынок ограничен, а сферы деятельности компании могут быть весьма специфичными и требующих узких специалистов.

\section{Выво $\triangle ы$}

Появление на финансовом рынке новых видов деривативов - производных финансовых инструментов обуславливается потребностью клиентуры в совершенствовании методов страхования от рисков. На сегодняшний день происходит постоянное совершенствование информационных технологий, механизмов образования цен и моделей управления рисками.

В современной российской экономике становится все более распространенным такие инструменты хеджирования, как свопы.

Стратегический инвестор не только оказывает положительное влияние на финансовую сторону компании, а также часто передает ей свои управленческие и деловые качества.

В начале выхода на предложение акций компании в основном предпочитают частное размещение, нежели публичное. Частное размещение во многом дублирует публичное. Привлеченные стратегические или портфельные инвесторы готовят 2-3 года компанию к выходу на публичное размещение акций, чтобы тем самым преумножить свое финансовое состояние.

Возможны и другие пути выхода на IPO, которые не включают в себя предварительные источники финансирования в виде портфельных инвесторов. Однако для этого должны выполняться ряд необходимых условий. Компания должна быть известна рынку, иметь хорошую деловую репутацию, высокую капитализацию (для оценки можно привлечь экспертную группу). Но привлечение экспертной группы также является рисковым, поскольку реальную оценку компании может дать только рынок.

При публичном размещении своих акций компании берут на себя большую ответственность, помимо привлечения финансирования. Компания должна быть готова к дополнительным расходам на оплату услуг андеррайтера, рекламных агентов, юрисконсультов, расходы на услуги клиринговых услуг, а также оплату услуг самой биржи. Акционеры компании также должны следить за торгуемыми на бирже долями, поскольку при покупке инвесторами большей доли есть риск потери управления компанией.

Рассмотрев основные концепции привлечения капитала можно сделать вывод, что наиболее ответственным и сложным является выход компаний на публичный рынок размещения акций. 


\section{ЛИТЕРАТУРА}

1. Сайт информационных и аналитических услуг.—URL: https://www.capitaliq.com (дата обращения 10.11.2020) — Режим доступа: для зарегистрированных пользователей. - Текст: электронный.

2. Auzair S. Organisational Life Cycle Stages and Management Control Systems in Service Organisations. International Journal of Business and Management. Toronto. Nov. 2010.

3. Отекина Е. Младенцам — кредиты, зрелым — IP0. Консультант. № 13. 2007.

4. Широкова Г.В. Жизненные циклы российских предпринимательских фирм: методология исследования и основные стадии. - Автореферат диссертации на соискание ученой степени доктора экономических наук. - СПб.: СПбГУ, 2010. - 45 с.

5. Российские учителя в свете исследовательских данных. Отв. ред.: И.Д. Фрумин, В.А. Болотов, С.Г. Косарецкий, М. Карной. М.: Издательский дом НИУ ВШЭ, 2016.-С. 4.

6. Зябрикова А.В., Зябриков В.В. Развитие теории жизненного цикла на основе единой типологии деловой культуры // Проблемы современной экономики, N1 (53), 2015. С. 116-120.

7. Будова Е.В. Особенности управления бизнес-процессами в компаниях, находящихся на этапе «зрелости» кривой жизненного цикла // Вопросы отраслевого управления, 2013, № 1. С. 35-44.

8. Потина Е.В. Диагностика стадий жизненного цикла организации. Управление образованием: сборник статей. Вып. 5 под общей ред. Н.А. Заиченко; С.А. Михеевой; Санкт-Петербургский филиал Нац. исслед. ун-та «Высшая школа экономики».— СПб: Отдел оперативной полиграфии НиУ ВШэ — Санкт-Петербург, 2016. с. 112-115.

9. Borodin, A.; Tvaronavičienè, M.; Vygodcyikova, I.; Kulikov, A.; Skuratova, M.; Shchegolevatykh, N. Improving the Development Technology of an Oil and Gas Company Using the Minimax Optimality Criterion. Energies. 2021, 14, 3177

10. Borodin A, Mityushina I, Streltsova E, Kulikov A, Yakovenko I, Namitulina A. Mathematical Modeling for Financial Analysis of an Enterprise: Motivating of Not Open Innovation. Journal of Open Innovation: Technology, Market, and Complexity. 2021; 7(1):79.

11. Щетинина Е.Д., Шемякина А.Е. Определение этапа жизненного цикла продукта и особенности маркетинговых мероприятий на различных этапах жизненного цикла. Белгородский экономический вестник. 2021. № 1 (101). С. 59-63

12. Козлова 0.С. Влияние региональных фаз жизненного цикла нефтедобычи на длительность жизненного цикла отрасли. Известия Байкальского государственного университета. 2017. Т. 27. № 1. С. 27-31

13. Бегун М.А. Отдельные аспекты управления жизненным циклом и применение метода анализа затрат жизненного цикла при выборе воздействия на физические производственные активы электросетевых организаций. Экономика: вчера, сегодня, завтра. 2020. Т. 10. № 9-1. С. 139-152.

14. Kharitonovich A.V. The analysis of life cycle of the investment and construction sector. Components of scientific and technological progress. 2020. № 2 (44). C. $13-25$.

15. Тузовская 0.С. Анализ обоснования формы финансирования компании с учётом стадии ее жизненного цикла. Теория и практика современной науки. 2016. № 6-2 (12). С. 244-247.

16. Каримов Т.Р. К возможности применения модели управления стимулированием инновационной деятельностью на основе жизненного цикла в нефтеперерабатывающем предприятии. Социально-экономические исследования, гуманитарные науки и юриспруденция: теория и практика. 2016. № 9. C. 71-76.

17. Ваничева Е.А., Никифорова С.В. Обоснование выбора инструментов маркетинга на различных этапах жизненного цикла стартапа. Тенденции развития науки и образования. 2016. № 18-2. С. 9-12.

18. Лавриненко Е.А. Модели и методы системы упреждающего мониторинга на начальном этапе жизненного цикла инвестиционного проекта. Новая наука: Современное состояние и пути развития. 2016. № 10-1. С. 95-99.

19. Пахтусова В.Н. Особенности деятельности компании на разных этапах жизненного цикла. Novalnfo.Ru. 2017. Т. 5. № 58. С. $213-219$.

( З Зайцев Владислав Александрович (vladz2210@mail.ru ).

Журнал «Современная наука: актуальные проблемы теории и практики» 